\title{
Genetic parameters for ewe reproduction with objectively measured wool traits in Elsenburg Merino flock
}

\author{
P. A. M. Matebesi-Ranthimo ${ }^{1,2 \#}$, S. W. P. Cloete $^{3,4}$, J. B. van Wyk ${ }^{2}$ \& J. J. Olivier ${ }^{4}$ \\ ${ }^{1}$ National University of Lesotho, P.O. Roma 180, Roma Lesotho \\ ${ }^{2}$ University of the Free State, P.O. Box 339, Bloemfontein 9300, South Africa \\ ${ }^{3}$ University of Stellenbosch, Private Bag X1, Matieland, 7602, South Africa \\ ${ }^{4}$ Institute for Animal Production: Private Bag X1, Elsenburg, Western Cape, 7609, South Africa
}

(Received 28 July 2016; Accepted 26 July 2017; First published online 14 September 2017)

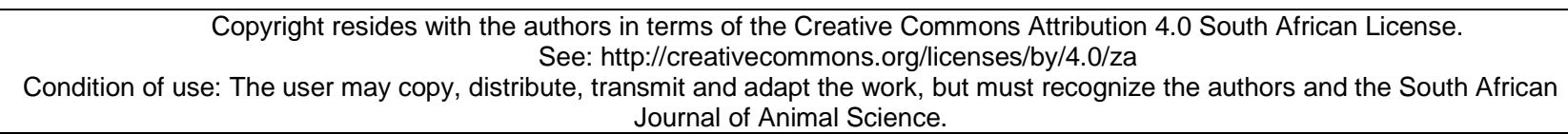
Journal of Animal Science.

\begin{abstract}
Reproduction is important for sustainable lamb production in Merino sheep. Data from a Merino flock maintained at Elsenburg Research Farm in the Western Cape, South Africa, were used to investigate the genetic parameters for ewe reproduction traits and their relationship with objectively measured wool traits. Traits included number of lambs born during the first lambing opportunity (NLB1), number of lambs weaned during the first lambing opportunity (NLW1), total weight of lamb weaned during the first lambing opportunity (TWW1), number of lambs born during a ewe's lifetime (NLB3), number of lambs weaned during a ewe's lifetime (NLW3), and total weight weaned per ewe's reproductive life (TWW3) Fixed effects of selection line, birth type, sex, age of the dam in years, year of birth, and the sex*birth year interaction had significant effects on all bodyweight and objectively measured wool traits. Only year of birth and selection line affected ewe reproduction traits. Heritability estimates amounted to $0.10 \pm 0.03$ for NLB1, $0.07 \pm 0.02$ for NLW1, $0.10 \pm$ 0.04 for TWW1, $0.25 \pm 0.04$ for NLB3, $0.12 \pm 0.03$ for NLW3, and $0.18 \pm 0.04$ for TWW3. Wool traits were moderately heritable at $0.28 \pm 0.05$ (staple strength) to $0.60 \pm 0.03$ (clean yield (CY)) and coefficient of variation of fibre diameter (CVFD). Relationships among ewe reproduction traits were high, ranging from 0.74 between TWW1 and NLB3 to 1.00 between NLW1 and TWW1. The genetic relationships of ewe reproduction traits with wool weights and staple length were positive. Fibre diameter (FD) and CY were unfavourably related to ewe reproduction traits. It seems possible to improve ewe reproduction when selecting on NLB, NLW, and TWW in Merino sheep without unwanted correlated response to selection in wool traits, with the exception of FD and CY.
\end{abstract}

Keywords: Bodyweight, heritability, relationships

\#Corresponding author: pmatebesi@gmail.com

\section{Introduction}

South African Merino sheep have traditionally been selected mainly for wool traits, body conformation and bodyweight (Olivier et al., 1995; Olivier, 2014). Global demand and prices for sheep meat have interested Merino breeders in selection for animals that could be slaughtered for meat, but could still produce quality wool. Research for inclusion of ewe reproduction in South African Merinos has emphasized net reproduction rate (Olivier, 1999). Earlier investigations (Dickerson, 1970) have stressed the importance of reproduction and mothering ability of ewes, and growth and survival of lambs for efficient lamb production to satisfy the demand for quality wool and meat by consumers. Research has suggested the possibility of improving ewe reproduction genetically through direct and indirect selection because of its composite nature (Olivier et al., 2001; Cloete, 2002; Huisman \& Brown 2008; Snowder \& Fogarty, 2009). However, it was contended that selection for a component of a composite trait does not always result in an overall improvement of a complex trait such as ewe reproduction (Snowder \& Fogarty, 2009).

Total weight of lamb weaned per ewe mated (also a composite trait) depending on fertility, litter size, weight of individual lambs, mothering ability, and embryonic and lamb survival (Van Wyk et al., 2003) was widely used to select ewes for reproduction performance. Genetic parameters were also estimated for this trait, but relatively few studies investigated the relationship between ewe reproduction and objectively measured wool traits such as staple length, staple strength, fibre diameter and coefficient of variation of fibre diameter. The inclusion of ewe reproduction in woolled sheep breeding is still problematic, despite the 
economic importance of reproduction, owing to its complex nature. Knowledge of the nature of the relationships between ewe reproduction and economically important wool traits is thus essential to derive appropriate selection programmes in the South African Merino sheep industry. The objective of this study was thus to estimate the heritability of reproduction and wool traits in South African Merino, as well as genetic, phenotypic and environmental correlations.

\section{Material and methods}

A resource flock of Merino sheep that is maintained at Elsenburg Research Farm in the Western Cape, South Africa, provided data for this investigation. These animals were divergently selected initially for their ability to rear multiples since 1986 using maternal ranking values for lambs reared per joining, which was subsequently aided by single-trait repeatability model breeding values as described by Cloete et al. (2003; 2004; 2009). The animals providing data were progeny born between 1986 and 2012. The number of records included in the data ranged from 1049 for reproduction traits for the first three parities to 4748 for yearling and hogget wool traits. The pedigree included 4905 animals, the progeny of 241 sires and 1502 dams. The descriptive statistics of the data used are presented in Table 1.

Cloete \& Durand (1994) described the selection procedure of replacements in the flock, followed by Cloete \& Scholtz (1998), and subsequently by Cloete et al. (2004; 2009) and Scholtz et al. (2010). Ram and ewe progeny of ewes rearing more than one lamb per joining were preferred as replacements in the high $(\mathrm{H})$ line, while descendants of ewes rearing fewer lambs per joining were used as replacements in the lower (L) line. Selection decisions were based mostly on $\geq 3$ maternal joinings, particularly in rams. Selected ewes remained in the breeding flock for five joinings, if not incapacitated by death or culled for teeth or udder malfunctioning.

Table 1 Descriptive statistics of ewe reproduction and objective wool traits data after editing from Elsenburg Merino resource flock

\begin{tabular}{|c|c|c|c|c|c|}
\hline Trait & $\mathbf{n}$ & Mean & SD & CV (\%) & Range \\
\hline \multicolumn{6}{|l|}{ Ewe reproduction traits } \\
\hline Number of lambs born per ewe in the first parity (NLB1) & 1435 & 0.96 & 0.56 & 58.33 & $0-3$ \\
\hline Number of lambs weaned per ewe in the first parity (NLW1) & 1435 & 0.74 & 0.56 & 58.33 & $0-2$ \\
\hline Total weight weaned per ewe in the first parity (TWW1) & 1435 & 15.79 & 12.10 & 76.63 & $0-56.1$ \\
\hline $\begin{array}{l}\text { Number of lambs born per ewe over three lambing } \\
\text { opportunities (NLB3) }\end{array}$ & 1049 & 3.40 & 1.31 & 38.53 & $0-7$ \\
\hline $\begin{array}{l}\text { Number of lambs weaned per ewe over three lambing } \\
\text { opportunities (NLW3) }\end{array}$ & 1049 & 2.67 & 1.27 & 47.56 & $0-6$ \\
\hline $\begin{array}{l}\text { Total weight weaned per ewe over three lambing } \\
\text { opportunities (TWW3) }\end{array}$ & 1049 & 58.09 & 27.21 & 46.84 & $0-132.5$ \\
\hline \multicolumn{6}{|l|}{ Objective wool traits } \\
\hline Greasy fleece weight $(\mathrm{kg})$ & 4747 & 3.23 & 1.64 & 50.77 & $1.0-10.2$ \\
\hline Clean yield (\%) & 4747 & 74.76 & 4.91 & 6.57 & $49.7-99.2$ \\
\hline Clean fleece weight $(\mathrm{kg})$ & 4747 & 2.38 & 1.12 & 47.06 & $0.7-6.9$ \\
\hline Staple length (mm) & 3700 & 75.68 & 25.37 & 33.52 & $31-149$ \\
\hline Staple strength (N/ktex) & 1965 & 47.48 & 11.60 & 24.43 & $5-85$ \\
\hline Fibre diameter $(\mu \mathrm{m})$ & 4748 & 19.27 & 1.57 & 8.15 & $14.0-29.1$ \\
\hline Coefficient of variation of fibre diameter (\%) & 3063 & 29.09 & 3.13 & 10.76 & $13.5-37.0$ \\
\hline
\end{tabular}

n: number of records, SD: standard deviation, CV: coefficient of variation

The two lines were maintained as a single flock initially at Tygerhoek Experimental Farm near Riviersonderend in Western Cape, South Africa, from 1986 to 1992. At the end of 1992, the animals were transferred to Elsenburg Research Farm near Stellenbosch for studies on lambing behaviour (Cloete \& Scholtz, 1998; Cloete, 2002). Other details of the locality, management practices and recording of data in this flock can be found in the literature (Cloete \& Scholtz, 1998; Cloete et al., 2003; Cloete et al., 2004; Cloete et al., 2009). Traits included in the analyses were ewe reproduction traits, which included number of 
lambs born (NLB1), number of lambs weaned (NLW1), and total weight weaned (TWW1) per ewe at first parity at two years of age, number of lambs born (NLB3), number of lambs weaned (NLW3) and total weight of lamb weaned (TWW3) per ewe over a three-year period from their lambing opportunities at two years of age to four years of age; objectively measured wool traits included greasy fleece weight (GFW), clean fleece weight (CFW), clean yield (CY), fibre diameter (FD), staple length (SL), and staple strength (SS). A measurement of the variability of FD was included in the analysis, namely the coefficient of variation of FD (CVFD). Greasy fleece weight was recorded at shearing (August-September at Tygerhoek and May-June at Elsenburg) each year, while the measurements of quality were determined on a midrib wool sample taken from each animal at shearing. Clean fleece weight was calculated from greasy fleece weight and clean yield.

The ASREML program (Gilmour et al., 2009) was used to overview the data structure and to assess the distribution and feasibility of the records in the datasets. All animals without a sire or dam, birth type or sex were excluded. Dams aged seven years and older were pooled. Triplets and twins were pooled as multiples. Animals with a missing record for a particular trait were excluded from the analysis of that trait.

The significance of fixed effects for ewe reproduction and objectively measured wool traits was also tested, leaving only significant effects in the final operational model. Fixed effect solutions from the analyses were consistent with those reported in the literature, and thus were not presented and discussed further to avoid duplication. However, it is important to highlight the results from the current study and literature (Cloete et al., 2004), which indicated that selection line affected reproduction data in this flock, where $\mathrm{H}$ outperformed L for NLB, NLW, and TWW. Therefore, selection line was included as a fixed effect to correct for the differences between the lines. Exclusion of selection line in the operational model for these traits resulted in inflated heritability for ewe reproduction traits.

Random terms, which included a combination of direct additive, maternal additive and maternal permanent environmental effects, and the covariation between direct additive and maternal additive effects were then added, resulting in six single-trait mixed animal models:

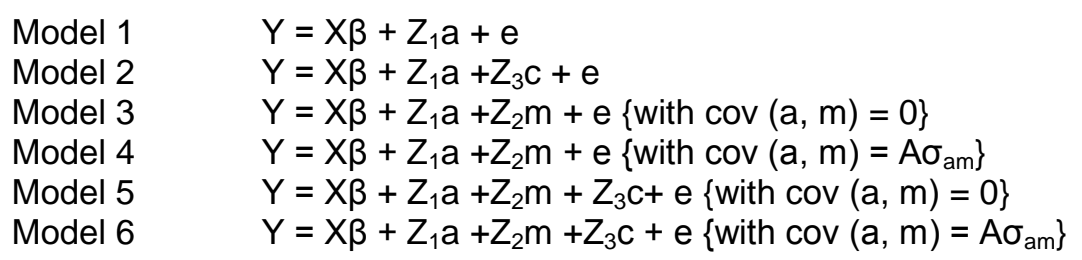

where: $\mathbf{Y}$ is a vector of observations

$\boldsymbol{\beta}$ is a vector of fixed effects influencing traits

$\mathbf{a}, \mathbf{m}$ and $\mathbf{c}$ are vectors of direct additive, maternal additive, (dam) permanent maternal environmental

$\mathbf{e}$ is residual effects

$X, Z_{1}, Z_{2}$ and $Z_{3}$ are incidence matrices relating observations to their fixed and random effects. It was assumed that:

$$
V(a)=A \sigma_{a}^{2} ; V(m)=A \sigma_{m}^{2} ; V(c)=I \sigma_{c}^{2} ; V(e)=l \sigma_{e}^{2}
$$

where: $\mathbf{A}$ is the numerator relationship matrix among animals in the pedigree file $I$ is an identity matrix.

The variances, $\sigma_{a}^{2}, \sigma_{m}^{2}, \sigma_{c}^{2}, \sigma_{e}^{2}$, were defined as direct genetic variance, maternal genetic variance, permanent environmental variance due to the dam and residual (error) variance, respectively. The phenotypic variance $\left(\sigma_{p}^{2}\right)$ was defined as the sum of all variance components estimated in the model of analysis, and could be derived from all of these variances, as appropriate for that analysis. Direct heritability estimates were calculated as $\sigma_{a}^{2} / \sigma_{p}^{2}$ and maternal heritability as $\sigma_{m}^{2} / \sigma_{p}^{2}$.

Random effects were tested for significance using log likelihood ratio tests after the sequential inclusion of random effects to the model. A random effect was considered significant when its inclusion in the model caused a significant improvement in the log likelihood ratio. A chi-square distribution of $\alpha=0.05$ at one degree of freedom was used as a test statistic (3.841). When -2 times the difference between the log likelihoods was greater than this critical value, the inclusion of the particular random effect was considered to significantly improve the fit (Swalve, 1993). Various models were tested for significance to identify the best and simplest models that could be used for subsequent runs. Variance ratios were computed using estimated variance components obtained from single-trait analysis. A series of two-trait analyses were then 
conducted to estimate the genetic, phenotypic and environmental correlations among ewe reproduction traits, and between ewe reproduction traits and objectively measured wool traits.

\section{Results and discussion}

Fixed effects of selection line $(\mathrm{H}$ and $\mathrm{L})$, year of birth $(1968-2012)(P<0.001)$ and their interaction $(P$ $<0.01)$ fitted the data best for all ewe reproduction traits. A similar set of fixed effects combined with birth type (single/multiple), age of dam $\left(2-7^{+}\right)$and sex $x^{*}$ ear interaction significantly $(P<0.05)$ affected all objectively measured wool traits, and were included in the models used for subsequent analyses. These results are broadly consistent with the literature.

The log likelihood values for six models obtained from single-trait analyses are presented in Table 2. The model with only direct additive random effects best fits the data for all ewe reproduction traits, and was therefore used to analyse these traits. This is consistent with the majority of studies on sheep for corresponding ewe reproduction traits (Olivier et al., 2001; Duguma et al., 2002; Huisman et al., 2008; Zishiri et al., 2013). The results from the current study also indicated that only the direct additive effect had a significant contribution to variation in CY, SL, SS, and CVFD. Inclusion of additive maternal effects resulted in significant increments in the log likelihood values for CFW and FD. In addition to direct and maternal additive effects, their covariance contributed significantly to the variation in GFW.

Table 2 Log likelihood ratios for random effects model fitted to ewe reproduction and objectively measured wool trait data of Elsenburg Merino resource flock with 'best' model in bold print

\begin{tabular}{|c|c|c|c|c|c|c|}
\hline Trait & Model 1 & Model 2 & Model 3 & Model 4 & Model 5 & Model 6 \\
\hline $\begin{array}{l}\text { Number of lambs born per ewe in } \\
\text { the first parity (NLB1) }\end{array}$ & 31.8674 & 31.8676 & 32.6267 & 32.6277 & 32.6276 & 32.6277 \\
\hline $\begin{array}{l}\text { Number of lambs weaned per ewe } \\
\text { in the first parity (NLW1) }\end{array}$ & 40.0519 & 40.0519 & 40.2380 & 40.7917 & 40.2380 & 40.7917 \\
\hline $\begin{array}{l}\text { Total weight weaned per ewe in the } \\
\text { first parity (TWW1) }\end{array}$ & -4065.43 & -4065.43 & -4065.39 & -4064.96 & -4065.39 & -4064.96 \\
\hline $\begin{array}{l}\text { Number of lambs born per ewe } \\
\text { over three lambing opportunities } \\
\text { (NLB3) }\end{array}$ & -737.548 & -737.548 & -737.548 & $\mathrm{~N} / \mathrm{C}$ & -737.548 & $\mathrm{~N} / \mathrm{C}$ \\
\hline $\begin{array}{l}\text { Number of lambs weaned per ewe } \\
\text { over three lambing opportunities } \\
\text { (NLW3) }\end{array}$ & -709.617 & -709.617 & -709.617 & $\mathrm{~N} / \mathrm{C}$ & -709.617 & $\mathrm{~N} / \mathrm{C}$ \\
\hline $\begin{array}{l}\text { Total weight weaned per ewe of } \\
\text { three lambing opportunities } \\
\text { (TWW3) }\end{array}$ & -3649.44 & -3649.44 & -3649.44 & -3648.78 & -3649.44 & -3648.05 \\
\hline Greasy fleece weight (GFW) & 435.552 & 446.134 & 447.948 & 450.917 & 430.928 & 433.320 \\
\hline Clean yield (CY) & -8374.48 & -8374.48 & -8374.48 & $\mathrm{~N} / \mathrm{C}$ & -8374.48 & $\mathrm{~N} / \mathrm{C}$ \\
\hline Clean fleece weight (CFW) & 1708.84 & 1716.90 & 1722.41 & 1723.29 & 1722.41 & 1723.29 \\
\hline Staple length (SL) & -9650.43 & -9650.43 & -9650.39 & -9649.29 & -9650.39 & -9649.26 \\
\hline Staple strength (SS) & -5505.34 & -5504.96 & -5504.80 & -5504.55 & -5504.80 & -5504.55 \\
\hline Fibre diameter (FD) & -3266.39 & -3263.62 & -3261.16 & -3264.15 & -3263.24 & -3263.24 \\
\hline $\begin{array}{l}\text { Coefficient of variation of fibre } \\
\text { diameter (CVFD) }\end{array}$ & -4518.87 & -4518.24 & -4518.87 & $\mathrm{~N} / \mathrm{C}$ & -4518.24 & $\mathrm{~N} / \mathrm{C}$ \\
\hline
\end{tabular}

Model 1: only direct additive animal effects as random; Model 2: direct additive and dam permanent environment effects as random; Model 3: direct and maternal additive effects as random; Model 4: direct and maternal additive effects and their covariance as random; Model 5: direct additive, maternal additive and dam permanent environment effects as random; and Model 6: direct additive, maternal additive, dam permanent environment, covariance between animal effects as random effects; N/C: not significant

Genetic parameters for ewe reproduction and objective wool traits are presented in Table 3. Direct heritability $\left(h_{a}^{2}\right)$ was estimated at $0.10 \pm 0.03$ for NLB1, $0.07 \pm 0.02$ for NLW1, and $0.10 \pm 0.03$ for TWW1. Fogarty et al. (1994) reported a higher value for NLB1 $(0.20 \pm 0.08)$ than that reported in the current study using data from Hyfer sheep. The estimate for TWW1 in this study is higher than that of 0.02 reported earlier 
in the Tygerhoek Merino flock (Duguma et al., 2002). No corresponding results were found for NLW1 from the literature. A moderate $h^{2}$ was found for NLB3 at $0.25 \pm 0.04$. This moderate estimate is higher than the comparable value of 0.13 derived from literature values (Safari et al., 2005). Research in Merino resource flocks (Olivier et al., 2001; Duguma et al., 2002; Huisman et al., 2008; Pickering et al., 2012) reported slightly lower estimates $(0.19-0.23)$ for NLB3 compared with that obtained in the current study. The estimate of 0.07 derived from data of seven Australian resource flocks (Safari et al., 2007a) was appreciably lower than the value of 0.25 obtained for NLB3. A value of 0.04 estimated more recently for South African fine wool Merinos (Olivier, 2014) was also much lower than the current $h^{2}{ }_{a}$ estimate for NLB3. The estimates $(0.01-0.10)$ yielded from other sheep breeds of South Africa (Van Wyk et al., 2003; Olivier \& Cloete, 2006) and elsewhere (Vatankhah \& Talebi, 2008; Mokhtari et al., 2010; Boujenane et al., 2013) were also lower than the current $\mathrm{h}^{2}$ a of 0.25 . Previous analysis from the same Merino resource flock also yielded a lower value of 0.10 (Cloete et al., 2004). The differences between the current study and that of Cloete et al. (2004) may be because of the partitioning of random effects to direct additive and dam permanent environmental effects while using a repeatability model in the previous study.

Table 3 Covariance components and ratios for ewe reproduction and objectively measured wool traits in Elsenburg Merino flock

\begin{tabular}{|c|c|c|c|c|c|c|c|c|c|c|c|c|c|}
\hline & NLB1 & NLW1 & TWW1 & NLB3 & NLW3 & TWW3 & GFW & $\mathrm{CY}$ & CFW & SL & sS & FD & CVFD \\
\hline \multicolumn{14}{|c|}{ (Co)variance components } \\
\hline$\sigma_{a}^{2}$ & 0.02 & 0.01 & 10.25 & 0.38 & 0.16 & 71.59 & 0.15 & 9.72 & 0.06 & 28.00 & 31.76 & 0.93 & 5.40 \\
\hline$\sigma_{m}^{2}$ & - & - & - & - & - & - & 0.05 & & 0.02 & & & 0.05 & \\
\hline$\sigma_{\mathrm{am}}$ & - & - & - & - & - & - & -0.03 & & & & & & \\
\hline$\sigma_{e}^{2}$ & 0.28 & 0.28 & 125.6 & 1.10 & 1.19 & 523.8 & 0.17 & 6.48 & 0.11 & 50.98 & 83.59 & 0.75 & 3.61 \\
\hline$\sigma_{p}^{2}$ & 0.30 & 0.29 & 135.8 & 1.48 & 1.35 & 595.4 & 0.33 & 16.2 & 0.19 & 78.98 & 115.3 & 1.73 & 90.1 \\
\hline \multicolumn{14}{|c|}{ Variance ratios } \\
\hline$h_{a}^{2}$ & 0.10 & 0.07 & 0.10 & 0.25 & 0.12 & 0.18 & 0.45 & 0.60 & 0.31 & 0.33 & 0.28 & 0.54 & 0.60 \\
\hline $\mathrm{SE}$ & 0.03 & 0.02 & 0.03 & 0.04 & 0.03 & 0.04 & 0.04 & 0.03 & 0.04 & 0.04 & 0.05 & 0.04 & 0.04 \\
\hline $\mathrm{h}_{\mathrm{m}}^{2}$ & - & - & - & - & - & - & 0.14 & - & 0.09 & - & - & 0.03 & - \\
\hline SE & - & - & - & - & - & - & 0.03 & - & 0.02 & - & - & 0.01 & - \\
\hline$r_{\mathrm{am}}$ & - & - & - & - & - & - & -0.35 & - & - & - & - & - & - \\
\hline SE & - & - & - & - & - & - & 0.10 & - & - & - & - & - & - \\
\hline
\end{tabular}

NLB1: number of lambs born, NLW1: number of lambs weaned, TWW1: total weight weaned per ewe in the first parity, NLB3: number of lambs born, NLW3: number of lambs weaned, TWW3: total weight weaned per ewe over three lambing opportunities, GFW: greasy fleece weight, CFW: clean fleece weight, CY: clean yield, SL: staple length, SS: staple strength, FD: fibre diameter, CVFD: coefficient of variation of fibre diameter, $\sigma^{2}{ }_{a}$ : direct additive genetic variance, $\sigma^{2}$ : maternal additive genetic variance, $\sigma^{2}$ : residual variance, $\sigma_{p}^{2}$ : total phenotypic variance, $\sigma_{a m}$ : covariance between direct and maternal additive genetic effects, $h^{2}{ }_{a}=$ direct heritability, $h_{m}^{2}=$ maternal heritability and $r_{a m}$ : genetic correlation between direct and maternal additive genetic effects, SE: standard error

Number of lambs weaned per ewe joined over three lambing opportunities (NLW3) was heritable at $0.12 \pm 0.03$ in the current study. Comparable estimates for NLW3 suggested a range of 0.02 to 0.29 (Fogarty et al., 1994; Snyman et al., 1998b; 1998c; Olivier et al., 2001; Cloete et al., 2002; Duguma et al., 2002; Cloete et al., 2003; Van Wyk et al., 2003; Cloete et al., 2004; Safari et al., 2005; Olivier \& Cloete, 2006; Huisman et al., 2008; Vatankhah \& Talebi, 2008; Afolayan et al., 2009; Mokhtari et al., 2010; Rashidi et al., 2011; Mohammadi et al., 2012; Boujenane et al., 2013; Olivier, 2014). The current estimate of NLW3 is higher than the value of 0.05 derived from eight reports by Safari et al. (2005). Previous work in other South African Merino flocks yielded higher estimates of 0.17 and 0.16 (Olivier et al., 2001; Duguma et al., 2002). Recent work published lower $\mathrm{h}^{2}$ estimates in Merino (Huisman et al., 2008) and other sheep breeds (Vatankhah \& Talebi, 2008; Afolayan et al., 2009; Mokhtari et al., 2010; Rashidi et al., 2011; Mohammadi et al., 2012). More recently, Boujenane et al. (2013) reported a slightly lower value of 0.11 using data from the D'man sheep breed in Morocco. In addition, Olivier (2014) reported a low $h^{2}{ }_{a}$ estimate at 0.02 for a South African fine wool Merino line. 
The $\mathrm{h}^{2}$ a estimate for TWW3 amounted to $0.18 \pm 0.04$ in this study. This estimate fell within the range of comparable literature values (0.04-0.22) reported in sheep (Duguma et al., 2002; Cloete et al., 2004; Safari et al., 2005; Huisman et al., 2008; Vatankhah \& Talebi, 2008; Afolayan et al., 2009; Boujenane et al., 2013; Zishiri et al., 2013; Olivier, 2014) and goats (Rashidi et al., 2011). The current value of 0.18 is consistent with the recently reported estimate for Kermani sheep of Iran (Mokhtari et al., 2010) but slightly lower than 0.19 reported for Morada Nova sheep of Brazil (Shiotsuki et al., 2014). Previous research in South Africa yielded lower $\mathrm{h}^{2}$ a values that ranged from 0.07-0.11 for the Dorper sheep breed (Olivier \& Cloete 2006; Zishiri et al., 2013). Research on a South African fine Merino line suggested that TWW was low heritable at 0.02 (Olivier, 2014), which is markedly lower than the estimate from this study. The differences between the current results and literature values may be due to different models being used, whereas other studies indicated the effect of one or a combination of dam permanent environment with service sire effects on the expression of ewe productivity in repeatability model estimates.

The substantial number of studies on objectively measured wool traits in woolled sheep breeds included a comprehensive review by Safari et al. (2005). Matebesi et al. (2009a; 2009b) also studied objectively measured wool traits and their relationships with live weight and subjectively measured wool and conformation traits. (Earlier studies included in reviews by Safari et al. (2005) and Matebesi et al. (2009a; 2009b) will not be cited in this study unless pertinent to this investigation.)

All the objectively measured wool traits were heritable, with a range in $h^{2}$ a estimates from 0.31 for CFW and 0.60 for CY and CVFD (as presented in Table 3). The maternal genetic component was present only for GFW (0.14 \pm 0.03$)$, CFW $(0.09 \pm 0.02)$, and FD $(0.03 \pm 0.01)$ in this study. The significant covariance between animal effects was evident only for GFW among all these objective wool traits. These results are broadly consistent with the literature, and are covered well in Matebesi-Ranthimo et al. (2014). Therefore, they will not be discussed further to avoid duplication.

The genetic $\left(r_{g}\right)$, phenotypic $\left(r_{p}\right)$ and environmental $\left(r_{e}\right)$ correlations among ewe reproduction traits are illustrated in Table 4. There was a very high $r_{g}$ between NLB1 and the other ewe reproduction traits, suggesting that all ewe reproduction traits are controlled by a similar set of genes. NLW1 is the same trait as TWW1 and NLW3, as suggested by $r_{g}$-values of 1.00 (Table 4). A very high $r_{g}$ for NLW1 with NLB3 (0.92) and TWW3 (0.93) was also obtained. TWW1 was highly related to NLB3, NLW3 and TWW3. NLB3 and NLW3 were highly related at 0.93 , suggesting that the two traits were genetically similar. NLW3 and TWW3 were the same trait, as suggested by a very high and positive $r_{g}$ of 0.99 . The high genetic correlation between first reproduction traits and total reproduction was not entirely unexpected owing to the part-whole relationship between early reproduction and total reproduction.

Comparable results from the literature involving the same traits reported a range of high $r_{g}$ estimates (0.68-0.998) between NLB and NLW over a number of lambing opportunities. The current results are within the range of literature values, but higher than the value of 0.62 reported earlier (Duguma et al., 2002) for another South African Merino resource flock. Recent work on other sheep breeds (Rashidi et al., 2011; Mohammadi et al., 2012) also yielded lower genetic correlations at 0.68. More recently, Olivier (2014) suggested that NLB and NLW are the same trait owing to unity $r_{g}$-estimates between these traits.

The $r_{g}$-value of 0.86 obtained between NLB3 and TWW3 in this study is within the range of literature values (0.35-0.99) and in line with the South African Merinos report (Snyman et al., 1998a; Olivier, 2014). The value reported earlier on the same Merino resource flock (Cloete et al., 2004) is somewhat lower than the present value. These differences may be due to use of different models in the analysis. For example, Cloete et al. (2004) used a repeatability model on repeated reproduction records.

The relationships between NLW and TWW per ewe over more than one lambing opportunity were very high from the literature cited, with the exception of a moderate estimate of 0.41 reported for the Kermani sheep breed of Iran (Mokhtari et al., 2010). The current $r_{\mathrm{g}}$-estimate of 0.99 is higher than all the $r_{\mathrm{g}}$-estimates cited in the literature, but close to the value of 0.97 reported earlier for Merinos (Olivier et al., 2001).

Research on South African Merinos (Duguma et al., 2002) reported unity $r_{g}$-estimates between TWW1 and total weight weaned over four lambing opportunities (TWW). This is in agreement with the current $r_{g}$ of 0.79 estimated in this study. In their study Duguma et al. (2002b) reasoned that higher relationships between TWW1 and TWW could be expected because TWW1 forms part in the computation of TWW in a part-whole relationship. This is also the case in the present study. Phenotypic and environmental correlations were positive, and ranged from moderate to high in magnitude and were in agreement with those in the literature cited. 
Table 4 Genetic, environmental and phenotypic correlations among ewe reproduction traits in Elsenburg Merino resource flock

\begin{tabular}{|c|c|c|c|}
\hline Trait & Genetic $\left(r_{g}\right)$ & Environmental $\left(r_{e}\right)$ & Phenotypic $\left(r_{p}\right)$ \\
\hline \multicolumn{4}{|l|}{$N L B 1 X$} \\
\hline NLW1 & $0.96 \pm 0.19$ & $0.60 \pm 0.04$ & $0.61 \pm 0.02$ \\
\hline TWW1 & $0.88 \pm 0.19$ & $0.53 \pm 0.03$ & $0.56 \pm 0.02$ \\
\hline NLB3 & $0.96 \pm 0.08$ & $0.58 \pm 0.03$ & $0.64 \pm 0.02$ \\
\hline NLW3 & $0.95 \pm 0.21$ & $0.44 \pm 0.04$ & $0.49 \pm 0.02$ \\
\hline TWW3 & $0.98 \pm 0.15$ & $0.39 \pm 0.04$ & $0.47 \pm 0.03$ \\
\hline \multicolumn{4}{|l|}{$N L W 1 X$} \\
\hline TWW1 & $1.00 \pm 0.03$ & $0.93 \pm 0.01$ & $0.94 \pm 0.01$ \\
\hline NLB3 & $0.92 \pm 0.24$ & $0.36 \pm 0.04$ & $0.41 \pm 0.03$ \\
\hline NLW3 & $1.00 \pm 0.18$ & $0.58 \pm 0.03$ & $0.62 \pm 0.02$ \\
\hline TWW3 & $0.93 \pm 0.22$ & $0.56 \pm 0.03$ & $0.59 \pm 0.02$ \\
\hline \multicolumn{4}{|l|}{$T W W 1 X$} \\
\hline NLB3 & $0.80 \pm 0.20$ & $0.32 \pm 0.04$ & $0.38 \pm 0.03$ \\
\hline NLW3 & $0.81 \pm 0.19$ & $0.55 \pm 0.03$ & $0.58 \pm 0.02$ \\
\hline TWW3 & $0.79 \pm 0.16$ & $0.61 \pm 0.03$ & $0.63 \pm 0.02$ \\
\hline \multicolumn{4}{|l|}{ NLB3 X } \\
\hline NLW3 & $0.93 \pm 0.08$ & $0.67 \pm 0.03$ & $0.72 \pm 0.02$ \\
\hline TWW3 & $0.86 \pm 0.09$ & $0.61 \pm 0.03$ & $0.67 \pm 0.02$ \\
\hline \multicolumn{4}{|l|}{ NLW3 X } \\
\hline TWW3 & $0.99 \pm 0.02$ & $0.93 \pm 0.01$ & $0.94 \pm 0.00$ \\
\hline
\end{tabular}

NLB1: number of lambs born, NLW1: number of lambs weaned, TWW1: total weight weaned per ewe in the first parity, NLB3: number of lambs born, NLW3: number of lambs weaned, TWW3: total weight weaned per ewe over three lambing opportunities

Genetic, environmental and phenotypic correlations of ewe reproduction traits at first parity and over three lambing opportunities with wool traits are presented in Tables 5 and 6 , respectively. The $\mathrm{r}_{\mathrm{g}}$ of ewe reproduction traits with wool weight traits was positive and significant for NLW1 with CFW, TWW1 with GFW and CFW and for TWW3 with GFW and CFW. These results suggested an improvement in wool weight when selection is based on an increased number of lambs weaned per ewe mated and increased overall weight of lambs weaned.

Some earlier studies in South African Merinos (Snyman et al., 1998a; Cloete et al., 2004), Afrinos (Snyman et al., 1998c) and Australian Merinos (Cloete et al., 2002; Safari et al., 2007b) also yielded positive relationships between ewe reproduction and wool weight traits over a number of lambing opportunities. In contrast, the average $r_{g}$ derived by Safari et al. (2005) for ewe reproduction and wool weights was low, variable and negative in sign $(-0.05$ to -0.10$)$. More recently, Olivier (2014) reported unfavourable relationships of wool weight traits with ewe reproduction traits using data from the Cradock fine wool Merino line. The $r_{g}$ estimates of reproduction traits with $\mathrm{CY}$ were moderate, negative and only significant at first parity. Safari et al. (2007b) reported a negative correlation between CY and litter size (corresponding with NLB in this study), but the estimate was not different from zero at $-0.06 \pm 0.04$. Recent work from South African fine wool Merinos also reported negative genetic correlations between ewe reproduction and $\mathrm{CY}$ (Olivier, 2014), which is in agreement with the results of this study. 
Table 5 Correlations (SE) between ewe reproduction at first parity and objectively measured wool traits in Elsenburg Merino flock

\begin{tabular}{|c|c|c|c|}
\hline Trait & Genetic $\left(r_{g}\right)$ & Environment $\left(r_{e}\right)$ & Phenotypic $\left(r_{p}\right)$ \\
\hline \multicolumn{4}{|c|}{ Number of lambs born per ewe at first parity (NLB1) X } \\
\hline Greasy fleece weight & $0.21 \pm 0.14$ & $-0.01 \pm 0.04$ & $0.04 \pm 0.02^{*}$ \\
\hline Clean yield & $-0.33 \pm 0.14^{*}$ & $-0.11 \pm 0.05^{\star}$ & $-0.02 \pm 0.03$ \\
\hline Clean fleece weight & $0.13 \pm 0.14$ & $0.03 \pm 0.04$ & $0.05 \pm 0.03$ \\
\hline Staple length & $0.15 \pm 0.15$ & $0.05 \pm 0.04$ & $0.07 \pm 0.03^{*}$ \\
\hline Staple strength & $-0.44 \pm 0.21^{*}$ & $-0.01 \pm 0.05$ & $-0.08 \pm 0.04$ \\
\hline Fibre diameter & $0.13 \pm 0.12$ & $0.05 \pm 0.04$ & $0.07 \pm 0.03^{*}$ \\
\hline Coefficient of variation of fibre diameter & $-0.08 \pm 0.14$ & $0.03 \pm 0.06$ & $-0.01 \pm 0.05$ \\
\hline \multicolumn{4}{|c|}{ Number of lambs weaned per ewe at first parity (NLW1) $X$} \\
\hline Greasy fleece weight & $0.44 \pm 0.20^{*}$ & $0.05 \pm 0.03$ & $0.10 \pm 0.03^{*}$ \\
\hline Clean yield & $-0.41 \pm 0.19^{*}$ & $0.14 \pm 0.05^{*}$ & $0.01 \pm 0.03$ \\
\hline Clean fleece weight & $0.28 \pm 0.20$ & $0.09 \pm 0.04^{*}$ & $0.11 \pm 0.03^{*}$ \\
\hline Staple length & $0.21 \pm 0.21$ & $0.02 \pm 0.04$ & $0.05 \pm 0.03$ \\
\hline Staple strength & $-0.23 \pm 0.31$ & $-0.03 \pm 0.05$ & $-0.05 \pm 0.03$ \\
\hline Fibre diameter & $0.01 \pm 0.17$ & $0.08 \pm 0.04$ & $0.05 \pm 0.03$ \\
\hline Coefficient of variation of fibre diameter & $-0.31 \pm 0.18$ & $-0.01 \pm 0.05$ & $-0.06 \pm 0.03^{*}$ \\
\hline \multicolumn{4}{|c|}{ Total weight of lamb weaned per ewe at first parity (TWW1) X } \\
\hline Greasy fleece weight & $0.55 \pm 0.14^{*}$ & $0.01 \pm 0.04$ & $0.12 \pm 0.03$ \\
\hline Clean yield & $-0.33 \pm 0.15^{\star}$ & $0.15 \pm 0.05$ & $0.01 \pm 0.02$ \\
\hline Clean fleece weight & $0.46 \pm 0.15^{\star}$ & $0.06 \pm 0.04$ & $0.13 \pm 0.03$ \\
\hline Staple length & $0.30 \pm 0.16$ & $0.01 \pm 0.04$ & $0.07 \pm 0.03$ \\
\hline Staple strength & $-0.09 \pm 0.24$ & $-0.03 \pm 0.05$ & $-0.04 \pm 0.04$ \\
\hline Fibre diameter & $0.09 \pm 0.13$ & $0.07 \pm 0.04$ & $0.07 \pm 0.03$ \\
\hline Coefficient of variation of fibre diameter & $-0.36 \pm 0.14^{*}$ & $-0.03 \pm 0.05$ & $-0.11 \pm 0.03^{*}$ \\
\hline
\end{tabular}

* Significant correlation; SE: standard error

Ewe reproduction and FD were positively related, but not significant, except for the $\mathrm{r}_{\mathrm{g}}$ between TWW3 and FD (Table 6). Safari et al. (2005) derived a positive value of 0.30 between NLB and FD. Previous research in South African Afrino sheep yielded a similar non-significant, but negative relationship between FD and NLW over three lambing opportunities (Snyman et al., 1998c). Dominic \& Swan (2016) found negative relationships between FD and NLW in Australian Merinos. Reproduction traits currently studied were negatively (i.e. favourably) related to CVFD and reached significance only between CVFD and TWW1. Comparable results were not found from the literature cited. Phenotypic and environmental correlations for ewe reproduction traits with objectively measure wool traits were low and variable in sign and generally accorded well with literature cited.

The results from this investigation suggested that ewe reproduction was positively related to SL and negatively related to $S S$, but that these relationships were not significant, barring the unfavourable $r_{g}$ between NLB1 and SS. A review by Safari et al. (2005) reported a moderate and negative correlation of 0.45 between NLW and SL derived from four studies. Similar correlations to the current study for SL with NLB and TWW were also reported (Safari et al., 2005). According to Olivier (2014), SL was positively related to ewe reproduction with the exception of the relationship with NLB which was negative but close to zero. The direction of $r_{g}$ between ewe reproduction and SS obtained in this study (negative) was different from that reported by Olivier (2014), which was positive. Attempts to find comparable studies were not successful. 
Table 6 Correlations (SE) between ewe reproduction over three lambing opportunities and objectively measured wool traits in Elsenburg Merino flock

\begin{tabular}{|c|c|c|c|}
\hline Trait & Genetic $\left(r_{g}\right)$ & Environment $\left(r_{\mathrm{e}}\right)$ & Phenotypic( $\left.r_{p}\right)$ \\
\hline \multicolumn{4}{|c|}{ Number of lambs born per ewe over three lambing opportunities (NLB3) $X$} \\
\hline Greasy fleece weight & $0.21 \pm 0.11$ & $0.01 \pm 0.05$ & $0.07 \pm 0.03^{*}$ \\
\hline Clean yield & $-0.11 \pm 0.11$ & $0.14 \pm 0.06^{\star}$ & $0.04 \pm 0.03$ \\
\hline Clean fleece weight & $0.19 \pm 0.12$ & $0.05 \pm 0.05$ & $0.09 \pm 0.03^{*}$ \\
\hline Staple length & $0.02 \pm 0.13$ & $0.10 \pm 0.05^{\star}$ & $0.06 \pm 0.03^{*}$ \\
\hline Staple strength & $-0.11 \pm 0.19$ & $-0.05 \pm 0.07$ & $-0.06 \pm 0.05$ \\
\hline Fibre diameter & $0.07 \pm 0.10$ & $0.06 \pm 0.05$ & $0.06 \pm 0.03^{*}$ \\
\hline Coefficient of variation of fibre diameter & $-0.08 \pm 0.12$ & $0.05 \pm 0.07$ & $0.04 \pm 0.03$ \\
\hline \multicolumn{4}{|c|}{ Number of lambs weaned per ewe over three lambing opportunities (NLW3) X } \\
\hline Greasy fleece weight & $0.26 \pm 0.15$ & $0.04 \pm 0.05$ & $0.09 \pm 0.03^{*}$ \\
\hline Clean yield & $-0.14 \pm 0.15$ & $0.16 \pm 0.05^{\star}$ & $0.06 \pm 0.03^{*}$ \\
\hline Clean fleece weight & $0.23 \pm 0.15$ & $0.09 \pm 0.05$ & $0.12 \pm 0.03^{*}$ \\
\hline Staple length & $0.03 \pm 0.17$ & $0.04 \pm 0.05$ & $0.03 \pm 0.03$ \\
\hline Staple strength & $-0.26 \pm 0.26$ & $0.03 \pm 0.06$ & $-0.02 \pm 0.05$ \\
\hline Fibre diameter & $0.23 \pm 0.13$ & $0.01 \pm 0.05$ & $0.07 \pm 0.03^{*}$ \\
\hline Coefficient of variation of fibre diameter & $-0.01 \pm 0.14$ & $0.05 \pm 0.07$ & $0.03 \pm 0.04$ \\
\hline \multicolumn{4}{|c|}{ Total weight of lamb weaned per ewe over three lambing opportunities (TWW3) $X$} \\
\hline Greasy fleece weight & $0.47 \pm 0.11^{*}$ & $-0.03 \pm 0.05$ & $0.09 \pm 0.03^{*}$ \\
\hline Clean yield & $-0.03 \pm 0.12$ & $0.14 \pm 0.05^{\star}$ & $0.08 \pm 0.03^{*}$ \\
\hline Clean fleece weight & $0.49 \pm 0.11^{*}$ & $-0.02 \pm 0.05$ & $0.13 \pm 0.03^{*}$ \\
\hline Staple length & $0.17 \pm 0.15$ & $0.02 \pm 0.04$ & $0.06 \pm 0.03^{*}$ \\
\hline Staple strength & $-0.23 \pm 0.23$ & $0.04 \pm 0.07$ & $-0.02 \pm 0.05$ \\
\hline Fibre diameter & $0.22 \pm 0.11^{*}$ & $0.01 \pm 0.05$ & $0.07 \pm 0.03^{\star}$ \\
\hline Coefficient of variation of fibre diameter & $-0.05 \pm 0.12$ & $0.06 \pm 0.06$ & $0.02 \pm 0.03$ \\
\hline
\end{tabular}

* Significant correlation; SE: standard error

\section{Conclusion}

Heritable ewe reproduction traits obtained in the current study indicated that selection is likely to result in genetic improvement over time. More importantly, the current results suggested high genetic correlations among reproduction traits, indicating that selection for NLB, NLW or TWW is likely to benefit the others as well. Selection for NLW as a component trait of TWW resulted in the improvement of TWW in South African Merinos. However, it is important to monitor progress closely when NLB is used, particularly in high reproducing flocks (such as the $\mathrm{H}$ Line) as this could have unwanted negative effects on lamb survival. The genetic correlations of reproduction traits with wool traits were favourable with few exceptions. It thus seems possible to improve ewe reproduction without serious unwanted correlated responses in wool traits, with the possible exceptions of FD, SS, and CY.

\section{Acknowledgements}

The contribution of Elsenburg technical staff to the maintenance and recording of the resource flock is acknowledged with gratitude. The research was funded jointly by the South African Wool Industry, OWSDW, Robert S. McNamara Fellowship Programme, National University of Lesotho and THRIP initiative of the National Research Foundation.

\section{Authors' contributions}

The study was conceived by SWCP, based on the PhD thesis of PAMMR, under the supervision of JBVW, SWCP and JJO. Data were collected by SWCP where analysis of data and interpretation of results were led by PAMMR with the 
assistance of SWCP and JBVW. The manuscript was drafted by PAMMR and critical revision and final approval of the version to be published were done by SWCP and JBVW.

\section{Conflict of Interest Declaration}

The authors declare that they have no conflicts of interest with regards to this work.

\section{References}

Afolayan, R.A. Fogarty, N.M., Morgan, J.E., Gaunt, G.M., Cummins, L.J. \& Gilmour, A.R., 2009. Preliminary genetic correlations of milk production and milk composition with reproduction, growth, wool traits and worm resistance in crossbred ewes. Small Rumin. Res. 82, 27-33.

Boujenane, I., Chikhi, A., Sylla, M. \& Ibnelbachyr, M., 2013. Estimation of genetic parameters and genetic gains for reproductive traits and bodyweight of D'man ewes. Small Rumin. Res. 113, 40-46.

Cloete, S.W.P., 2002. Studies on the behavioural and genetic aspects of ewe rearing ability and lamb survival in South African sheep flocks. PhD dissertation, University of Free State, Bloemfontein, South Africa.

Cloete, S.W.P. \& Durand, A., 1994. Reproduction of Merino sheep subjected to divergent selection on maternal values for lambs weaned per ewe joined. S. Afr. J. Anim. Sci. 24, 27-29.

Cloete, S.W.P. \& Scholtz, A.J., 1998. Lamb survival in relation to lambing and neonatal behavior in medium wool Merino lines divergently selected for ewe multiple rearing ability. Aust. J. Exp. Agric. 38, 801-811.

Cloete, S.W.P., Greeff, J.C. \& Lewer, R.P., 2002. Heritability estimates and genetic and phenotypic correlations of lamb production parameters with hogget live weight and fleece traits in Western Australian Merino sheep. Aust. J. Agric. Res. 53, 281-286.

Cloete, S.W.P., Misztal, I. \& Olivier, J.J., 2009. Genetic parameters and trends for lamb survival and birth weight in a Merino flock divergently selected for multiple rearing ability. J. Anim. Sci. 87, 2196-2208.

Cloete, S.W.P., Gilmour, A.R., Olivier, J.J. \& Van Wyk, J.B., 2003. Age trends in economically important traits of Merino ewes subjected to 10 years of divergent selection for multiple rearing ability. S. Afr. J. Anim. Sci. 31, 43-51.

Cloete, S.W.P., Gilmour, A.R., Olivier, J.J. \& Van Wyk, J.B., 2004. Genetic and phenotypic trends and parameters in reproduction, greasy fleece weight and live weight in Merino lines divergently selected for multiple rearing ability. Aust. J. Exp. Agric. 44, 745-754.

Cloete, S.W.P., Olivier, J.J., Snyman, M.A. \& Du Toit, E., 1998. Genetic parameters and trends in a selection experiment for increased clean fleece weight involving South African Merinos. Aust. J. Exp. Agric. 38, 427-432.

Dickerson, G. E., 1970. Efficiency of animal production. Molding the biological component. J. Anim. Sci. 30, 849-859.

Dominic, S. \& Swan A.A., 2016. Genetic and phenotypic parameters for reproduction, production and bodyweight traits in Australian fine-wool Merino sheep. Anim. Prod. Sci. https://doi.org/10.1071/AN15738

Duguma, G., Cloete, S.W.P., Schoeman, S.J. \& Jordaan, G.F., 2002. Genetic and environmental parameters for ewe productivity in Merinos. S. Afr. J. Anim. Sci. 32, 154-159.

Fogarty, N.M., Brash, L.D. \& Gilmour, A.R., 1994. Genetic parameters for reproduction and lamb production and their components and liveweight, fat depth and wool production in Hyfer sheep. Aust. J. Agric. Res. 45, 443-457.

Gilmour, A.R., Gogel, B.J., Cullis, B.R., Welham, S.J. \& Thompson, R., 2009. ASREM user guide release 3.0 VSN International, Hemel Hempstead, UK.

Huisman, A.E. \& Brown, D.J., 2008. Genetic parameters for bodyweight, wool, disease resistance and reproduction traits in Merino sheep. 1. Description of traits, model comparison, variance components and their ratios. Aust. J. Exp. Agric. 48, 1177-1185.

Huisman, A.E., Brown, D.J., Ball, A. J. \& Graser, H. U., 2008. Genetic parameters for bodyweight, wool, disease resistance and reproduction traits in Merino sheep. 1. Description of traits, model comparison, variance components and their ratios. Aust. J. Exp. Agric. 48, 1177-1185.

Matebesi, P.A., Cloete, S.W.P. \& Van Wyk, J.B., 2009a. Genetic parameter estimation of 16-month live weight and objectively measured wool traits in the Tygerhoek Merino flock. S. Afr. J. Anim. Sci. 39, 73-82.

Matebesi, P.A., Van Wyk, J.B. \& Cloete, S.W.P., 2009b. Relationships of subjectively assessed wool and conformation traits with objectively measured wool and live weight traits in the Tygerhoek Merino flock. S. Afr. J. Anim. Sci. 39, 188-196.

Matebesi-Ranthimo, P.A.M., Cloete, S.W.P., Van Wyk, J.B. \& Olivier, J.J., 2014. Genetic parameters and relationships of faecal worm egg count with objectively measured wool traits in the Tygerhoek Merino flock. S. Afri. J. Anim Sci. 44, 178-188.

Mohammadi, H., Shahrbabak, M.M. \& Shahrbabak, H.M., 2012. Genetic analysis of ewe productivity traits in Mokooei sheep. Small Rumin. Res. 107, 105-110.

Mokhtari, M.S., Rashidi, A. \& Esmailizader, A.K., 2010. Estimates of phenotypic and genetic parameters for reproductive traits in Kermani sheep. Small Rumin. Res. 88, 27-31.

Olivier, J.J., 1999. The South African Merino performance testing scheme. Proc. Assoc. Advmt Anim. Breed. Gen. 15, 119-124.

Olivier, J.J., Erasmus, G.J., Van Wyk, J.B. \& Konstantinov, K.V., 1995. Response to selection for BLUP of breeding values in the Grootfontein Merino stud. S. Afr. J. Anim. Sci. 25, 13-15.Olivier, J.J. \& Cloete, S.W.P. 2006. Genetic analysis of the South African Dorper sheep. In: Proc. World. Congr. Gen. Appl. Livest. Prod., Belo Horizonte August 13-18, 2006.

Olivier, W.J., 2014. The evaluation of a South African fine wool genetic resource flock. Ph.D. (Agric.) thesis, University of Stellenbosch, Stellenbosch, South Africa. 
Olivier, W.J., Snyman, M.A., Olivier, J.J., Van Wyk, J.B. \& Erasmus, G.J. 2001. Direct and correlated responses to selection for total weight of lamb weaned in Merino sheep. S. Afr. J. Anim. Sci. 31, 115-121.

Pickering, N.K., Dodds, K.G., Blair, H.T., Hickson, R.E., Johnson, P.L. \& McEwan, J.C., 2012. Genetic parameters for production traits in New Zealand dual-purpose sheep, with an emphasis on dagginess. J. Anim. Sci. 90, 14111420.

Rashidi, A., Mokhtari, M.S., Esmailizader, A.K. \& Asadi Fozi, M., 2011. Genetic analysis of ewe productivity traits in Moghani sheep. Small Rumin. Res. 96, 11-15.

Safari, E., Fogarty, N.M. \& Gilmour, A.R., 2005. A review of genetic parameter estimates for wool, growth, meat and reproduction traits in sheep. Livest. Prod. Sci. 92, 271-289.

Safari, E., Fogarty, N.M., Gilmour, A.R., Atkins, K. D., Mortimer, S. I., Swan, A. A., Brien, F. D., Greeff, J. C. \& Van der Werf, J. H. J., 2007. Across population genetic parameters for wool, growth, and reproduction traits in Australian Merino sheep. 2. Estimates of heritability and variance components. Aust. J. Agric. Res. 58, 177-184.

Safari, E., Fogarty, N.M., Gilmour, A.R., Atkins, K. D., Mortimer, S. I., Swan, A. A., Brien, F. D., Greeff, J. C. \& Van der Werf, J. H. J., 2007c. Genetic correlations among and between wool, growth and reproduction traits in Merino sheep. Aust. J. Anim. Breed. Genet. 124, 65-72.

Scholtz, A.J., Cloete, S.W.P., Van Wyk, J.B., Kruger, A.C.M. \& Van der Linde, T.C.de K., 2010. Influence of divergent selection for reproduction on the occurrence of breech strike in mature Merino ewes. Anim. Prod. Sci. 50, 203209.

Shiotsuki, L., Oliveira, D.P., Lôbo, R.N.B. \& Facó, O., 2014. Genetic parameters for growth and reproductive traits of Morada Nova sheep kept by smallholder in Semi-arid Brazil. Small Rumin. Res. http://dx.doi.org/10.1016/j.smallrumres.2014.05.009

Snowder, G.D. \& Fogarty, N.M., 2009. Composite trait selection to improve reproduction and ewe productivity: a review. Anim. Prod. Sci. 49, 9-16.

Snyman, M.A., Cloete, S.W.P. \& Olivier, J.J., 1998a. Genetic and phenotypic correlations of total weight of lamb weaned with bodyweight, clean fleece weight and mean fibre diameter in three South African Merino flocks. Livest. Prod. Sci. 55, 157-162.

Snyman, M.A., Erasmus, G.J. \& Van Wyk, J.B., 1998b. The possible genetic improvement of reproduction and survival rate in Afrino sheep using a threshold model. S. Afr. J. Anim. Sci. 28, 120-124.

Snyman, M.A., Erasmus, G.J., Van Wyk, J.B. \& Olivier, J.J., 1998c. Genetic and phenotypic correlations among production and reproduction traits in Afrino sheep. S. Afr. J. Anim. Sci. 28, 74-81.

Swalve, H.H., 1993. Estimation of direct and maternal (co)variance components for growth traits in Australian Simmental beef cattle. J. Anim. Breed. Genet. 110, 241-252.

Van Wyk, J.B., Fair, M.D. \& Cloete, S.W.P., 2003. Revised models and genetic parameter estimates for production and reproduction traits in the Elsenburg Dormer sheep stud. S. Afr. J. Anim. Sci. 33, (4) 213-222.

Vatankhah, M. \& Talebi, M.A., 2008. Heritability estimates and correlations between production and reproductive traits in Lori-Bakhtiara sheep in Iran. S. Afr. J. Anim. Sci. 38, 110-118.

Zishiri, O.T., Cloete, S.W.P., Olivier, J.J \& Dzama, K., 2013. Genetic parameters for growth, reproduction and fitness traits in the South African Dorper sheep breed. Small Rumin. Res. 112, 39-48. 